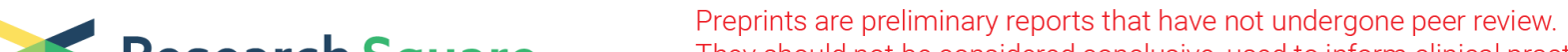 Research Square They should not be considered conclusive, used to inform clinical practice, or referenced by the media as validated information.
}

\section{The Influence of Male and Female Overweight/obesity on IVF Outcome: A Cohort Study Based on Registration in Western China}

xiang liu ( $\square$ liuxiang6366@163.com)

Women's and Children's Hospital https://orcid.org/0000-0001-7200-9467

Jianhua Sun

Northwest women's and childrens Hospital

Xia Xue

Northwest women's and children Hospital

Zhou Zhang

Northwest women's and children hospital

Juanzi Shi

Northwest women's and children Hosiptal

Junping Xing

Lanzhou University First Affiliated Hospital of xian jiaotong university oftal

\section{Research}

Keywords: Overweight/obese, body mass index (BMI, kg/m2), in vitro fertilization-embryo transform(IVF-ET), CPR, LBR

Posted Date: December 17th, 2020

DOl: https://doi.org/10.21203/rs.3.rs-127336/v1

License: (c) (i) This work is licensed under a Creative Commons Attribution 4.0 International License. Read Full License 


\section{Abstract}

Background: Overweight/obese couples are more likely to present with a lower fertility, but it is still unclear whether the Overweight/obese can reduce the successful rate of in vitro fertilization-embryo transform (IVFET).This systematic review uses strict Chinese BMI criterias to evaluate whether male and female overweight/obesity will affect embryo quality and IVF outcomes, and whether there are gender differences.

Methods: We reviewed the IVF-ET data of Northwest Women and Children's Hospital from 2015.01 to 2019.06, and divided the included population into four groups: Group 1 ( $\mathrm{n}=3413$, male and female BMl: $18.5 \leq \mathrm{BM} \mid \mathrm{Q} 24 \mathrm{~kg} / \mathrm{m} 2$, the control group);Group $2(\mathrm{n}=1437$, female BMI $\geq 24 \mathrm{~kg} / \mathrm{m} 2$ and male BMI $18.5 \leq B M \mid \otimes 24 \mathrm{~kg} / \mathrm{m} 2$, the experimental group 1); Group 3 ( $\mathrm{n}=4283$, female BMI $18.5 \leq \mathrm{BMI} \otimes 24 \mathrm{~kg} / \mathrm{m} 2$ and male BMl $\geq 24 \mathrm{~kg} / \mathrm{m} 2$, the experimental group 2) and Group 4 ( $n=2176$, female $B M I \geq 24 \mathrm{~kg} / \mathrm{m} 2$ and male $B M I \geq 24 \mathrm{~kg} / \mathrm{m} 2$, the experimental group 3). .Primary outcomes were clinical pregnancy rate, $₫ \mathrm{CPR})$, live birth rate(LBR)『available embryo rate and normal fertilization rate.

Results: The study found that the overweight/obesity of the independent female group or the combined male and female group manifested with a much less number of available embryos and a much less number of high-quality embryos $(p<0.05)$. Meanwhile, the independent male group displayed a significant reduction of IVF-ET cleavage rate $(p=0.019)$ and the independent female group displayed a significant reduction of the fertilization rate $(p=0.029)$ and the normal fertilization rate $(p=0.004)$. The combined male and female group manifested with a significant reduction of the available embryo rate $(p=0.026)$, the fertilization rate $(p=0.010)$ and the normal fertilization rate $(p=0.003) \llbracket$ but overweight/obesity has no significant effect on CPR LBRand abortion rates.

Conclusion: overweight/obesity affects the embryo quality, the fertilization rate, and the cleavage rate, and there exists gender differences. Therefore, in order to improve the embryo quality, the fertilization rate and the cleavage rate of IVF of overweight/obese couples, it is still recommended that one partner or both couples should manage to reduce their weight to a normal value before IVF treatment.

\section{Background}

Overweight / obesity has become an important global public health problem for it not only has a negative impact on the quality of life, but also has a severe impact on health [1]. Since 1980, the number of obese population worldwide has more than doubled[2], and according to expected demographic changes, the obese rate is expected to increase further[3]. At present, China is the country with the largest number of obese people in the world due to the large population and improvement of the economic status of people [4-6].Among Chinese adults, overweight/obesity accounts for $49.7 \%$ [7] and the number of obese people in China in 2014 was approximately 89.6 million (43.2 million men,46.4 million women)[8].

$\mathrm{BMI}$ is the key indicator for measuring overweight/obesity and based on European and American races, the World Health Organization (WHO) has established an international standard: the normal BMI range is $18.5-24.9 \mathrm{~kg} / \mathrm{m}^{2}$. A BMI of $25-29.9 \mathrm{~kg} / \mathrm{m}^{2}$ means overweight, and if $B M I \geq 30 \mathrm{~kg} / \mathrm{m}^{2}$, obesity should be considered. As Asian race is different from European and American races, the BMI standard of WHO is not rather suitable for Chinese people. For this reason, the BMI reference standard for Chinese adults is: $18.5-23.9 \mathrm{~kg} / \mathrm{m}^{2}$ is normal, $24-27.9 \mathrm{~kg} / \mathrm{m}^{2}$ is overweight, and $\geq 28 \mathrm{~kg} / \mathrm{m}^{2}$ is obese. Overweight/obesity can enhance the occurring rate of many diseases, and their occurrence and development are closely related to endocrine diseases, which can affect the functions of 
multiple human systems, such as the reproductive system. As a result, obesity will be a risk factor for menstrual disorders, ovulation disorders and infertility by reducing the chances of a woman's conception[9]. The risk of miscarriage can also increase as well. In theory, overweight/obesity will also reduce male fertility and fertility rate[10,11], because it reduces serum testosterone levels and increases serum estradiol levels, thereby impairing sperm function and increasing the risk of erectile dysfunction[12-14]. The semen parameters of male infertility patients indicate that an increase in waist circumference and BMI will reduce the ejaculation volume and increase the risk of oligospermia[15].In a recent cross-sectional cohort study, the decreased sperm concentration and the increased percentage of abnormal sperm morphology were also associated with obesity[16]. Most infertile couples need to use assisted reproductive technology (ART) to meet their fertile needs and IVF-ET is one of the most common ARTs. It is estimated that by 2100 , the number of people born with IVF-ET may reach $3.5 \%$ of the global population (about 400 million people)[17]. More than 2 million treatment cycles for IVF and Intracytoplasmic Sperm Injection (ICSI) are completed every year, it is estimated that the number of IVF oocyte retrieval cycles in China would increase from 684000 to 1326000 in 2018-2023.

Does overweight/obesity affect the outcome of IVF? If the answer is yes, is there a gender difference? There is still no definite conclusions concerning this aspect and some results may oppose the hypothesis. Actually, more and more evidences verify that female overweight/obesity can negatively affect ART outcomes [18-21].The influence of obesity on the outcome of ART even exceeds that of being overweight and implies a dose-response relationship[18-21], . Another study found that even in different races, obesity also affects CPR and abortion rate of ART. Most people suggest that it has less influence on ART outcome than female, or even has no effect on ART outcome [22-25]. Another study found that even in different races, obesity also affects the pregnancy rate and abortion rate of ART[26,27]. There is very little knowledge about the influence of male BMI on ART outcome and researchers hold controversial conclusions. Most people suggest that it has less influence on ART outcome than female, or even has no effect on ART outcome [28-30].Adversely, some scholars hold an opposite opinion: increasing male BMI can reduce the success rate of ART[31-33]. Further studies have found that male BMI is related to the insemination method of ART. Overweight males show a reduction in CPR or LBR of IVF treatment, but show no adverse effect on the outcome of ICSI treatment[34,35]. Previous studies are mostly based on the comparative analysis of ART outcomes based on the weight standards of European and American populations. Although China presents with the highest incidence of overweight/obesity, there are very few data on the IVF outcomes of Chinese overweight/obese populations. Therefore, we determined to study the impact of Chinese couples' BMI on the IVF outcome. Under the premise of excluding confounding factors affecting IVF outcome, we systematically reviewed and summarized the registered patients of IVF with overweight/overweight to investigate the impact of independent/combined male and female BMI on the outcome of assisted pregnancy after IVF treatment.

\section{Materials And Methods}

\section{population}

The subjects are those patients who have undergone IVF-ET assisted fertility treatment at the Reproductive Center of Northwest Women and Children's Hospital from 2015.01.01 to 2019.06.01. They were selected according to the following criteria: (1) they were at their first fresh oocyte retrieval cycle; (2)their menstrual period is regular; (3) the number of oocytes harvested $\geq 4$; (4) both couples are within the age of 22 to 36; (4) the causes of infertility are pelvic tubal disease and endometriosis; (4) both spouses have normal chromosomes; (5) in the past three months, 
no reproductive infections such as mycoplasma, chlamydia and gonorrhoeae had occurred. The subjects should also had no following conditions: (1) polycystic ovary syndrome (PCOS); (2) hyperprolactinemia; (3) diabetes and other diseases that may affect the test tube outcome. According to the obesity and overweight standards by the Chinese Obesity Working Group, they were divided into 4 groups: Group 1 ( $n=3413$, male and female BMl:

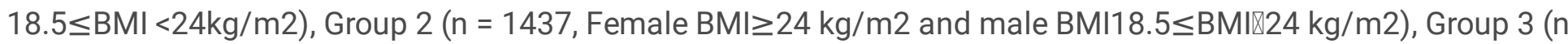

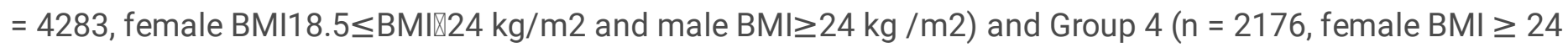
$\mathrm{kg} / \mathrm{m} 2$ and male $\mathrm{BMI} \geq 24 \mathrm{~kg} / \mathrm{m} 2$ )(Figure1).

\section{Research method}

The doctor used gonadotropin to enhance releasing hormone $(\mathrm{GnRH})$ agonist long protocol and antagonist protocol to promote ovulation. The subjects with normal or high-response ovarian response adopted the $\mathrm{GnRH}$ agonist long protocol, starting from the mid-luteal phase, subcutaneously inject triptorelin (Ferring $\mathrm{GmbH}$, Germany) $0.1 \mathrm{mg} / \mathrm{d}$ for 14 days. Gonadotropin(Gn) was injected after reaching the downregulating standard(Follicle-stimulating hormone(FSH) $₫ 5 \mathrm{U} / \mathrm{L}$, Luteinizing hormone(LH) $₫$ After $5 \mathrm{U} / \mathrm{L}$, Estradiol(E2) $<183 \mathrm{pmol} / \mathrm{L}$ ). The antagonist protocol was given $\mathrm{Gn}$ hyperstimulation from the $2 \mathrm{nd}$ to 3rd day of the menstrual cycle. From 5 to 6 days of hyperstimulation, cetrorelix acetate (Bayer, Germany) was injected subcutaneously at $0.25 \mathrm{mg} / \mathrm{d}$ to the day of human chorionic gonadotropin (HCG). When the diameter of more than 3 follicles is $\geq 18 \mathrm{~mm}$, HCG (Zhuhai Livzon, China) 5000 10000u was injected, and the oocytes were collected under the guidance of B ultrasound about 36 hours after the injection, and routine IVF treatment was performed 4 hours later. After fertilization, they were cultured in vitro for 72 to 120 hours, and at day 3, embryos or blastocysts were transferred. From the day of embryo/blastocyst transfer, $60 \mathrm{mg}$ progesterone injection (Zhejiang Xianju, China) was intramuscularly injected daily to 70 days after clinical pregnancy. A biochemical pregnancy is a biochemical pregnancy if the blood HCG is detected 12 to 14 days after the transplantation, and a clinical pregnancy is a clinical pregnancy if the gestational sac and fetal heart beat are observed by B ultrasound 4 to 6 weeks after transplantation.

\section{Evaluation standard of embryo and blastocyst}

Embryo grading. Grade I: The size of the blastomere is uniform without fragments; Grade II: The size of the blastomeres is uniform or slightly uneven, fragments $<20 \%$; Grade III: The size of the blastomeres is uniform or mildly uneven, fragments $20-50 \%$; Grade IV: The size of the blastomeres is uneven, and the fragments are more than $50 \%$. Grade I II are high-quality embryos, and Grade I III are transferable embryos.

Blastocysts were graded according to Gardner and Schoolcraft (1999). The blastocysts were classified into 1 to 6 grades according to the degree of expansion and hatching of the blastocysts. Then, according to the number of cells and the degree of cell adhesion, the inner cell mass and trophoblast cells were divided into $G$ rades $A$ to $C$. Blastocysts with scores $\geq 3 A A, 3 A B, 3 B A, 3 B B$ on day 5 , or blastocysts with scores $\geq 4 A A, 4 A B, 4 B A, 4 B B$ on day 6 to 7 are considered high-quality embryos.

\section{Laboratory analysis}

All serum was separated by centrifugation at $3500 \mathrm{rpm}$ for 5 minutes and kept at room temperature for 1 hour. The levels of FSH, LH, P and TES were measured by chemiluminescence microparticle immunoassay (Beckman DXI 800, USA). 


\section{Statistical analysis}

Descriptive statistics are presented as mean and standard deviation (SD). Continuous and categorical variables were compared between BMI groups using linear regression and group 1 as referent. Linear regression model was employed to assess the associations of BMI status and individual available embryo rate, high quality embryo rate, fertilization rate and cleavage rate by calculating b-coefficient and $95 \%$ confidence interval (Cl). Odds ratio (OR) and $95 \% \mathrm{Cl}$ were calculated using multivariate logistic regression model. Model 1 adjusted male and female age. Model 2 adjusted for female age, male age, year of infertility, E2 on HCG day, FSH on HCG day, P on HCG day, LH on HCG day, number of available embryos, left testicular volume, and right testicular volume. Two sides $P$ values less than 0.05 were considered significant. All analyses were conducted using Stata/SE 16.1.

\section{Results}

A total of 11,309 couples went through 6885 first fresh IVF-ET cycles. The number of first fresh IVF-ET cycles in group 1 to group 4 were 1954, 936, 2614, and 1381 respectively.

Table 1 shows that the basic data characteristics of the subjects. Although the testicular volume of the men in Group 3 and Group 4 was statistically different from that in Group $1(p<0.05)$, their bilateral testicular volumes were within the normal range (testicular volume $\geq 12 \mathrm{ml}$ ). Even if we restrict the age of both spouses: the age of both spouses is 22 to 36 years old, the baseline distribution of variables including age among the four groups is still unbalanced.

Table 2 shows the IVF outcomes between the four groups when the baseline imbalances of male and female age and other variables are not corrected. The data displays that there are no significant differences between the four groups in the available embryo rate, the high quality embryo rate, the cleavage rate, the implantation rate, CPR, abortion rate, and LBR ( $p>0.05)$. Compared with Group 1 and 2, Group 4 displays a lower fertilization rate and a normal fertilization rate $(p<0.05)$.

Table 3 shows the IVF outcomes between the four groups after when the baseline imbalance of male and female age and other variables are corrected. Compared with Group 1, the available embryo rate, the fertilization rate, and the normal fertilization rate of Group 2,3, and 4 are all significantly reduced ( $\beta$-coefficient $<0)$. The statistic results infer that independent/combined male and female BMI is a risk factor for CPR and LBR (OR>1). Compared with Group 1, Group 4 has significant statistical differences in the available embryo rate, the fertilization rate, and the normal fertilization rate $(\mathrm{p}<0.05)$, and Group 2 has significant statistical differences in the fertilization rate and the normal fertilization rate $(p<0.05)$.

\section{Discussion}

Although the ART outcome of overweight/obese couples during IVF treatment has received widespread attention, it is still controversial whether overweight/obese couples had a poor IVF outcome than the couples with a normal BMI. Does male and female BMI affect the outcome of IVF-ET? If yes, is the affection related to gender? What degree shall the IVF-ET outcomes would be specifically affected? The type of obesity in Chinese people is different from that of Europeans and Americans, most of which are abdominal obesity which is more likely to cause diseases such as myocardial infarction, cerebral infarction, diabetes, and hypertension. Is there any race differences in the IVF outcome of overweight/obese couples? 
Previous studies have shown that age and sex hormone levels can affect IVF outcomes [36, 37]. In our initial basic data, there are statistical differences in age and sex hormone levels (FSH days) between men and women in each group $(P<0.05)$. In order to reduce the influence of these factors, we established an adjustment model for age and other influencing factors. After excluding these factors, we found that compared with the couple with normal weight (Group 1), there is a significantly reduced IVF-ET cleavage rate $(P=0.019)$ in the independent male overweight / obese group and there is a reduced the fertilization rate $(p=0.029)$ and the normal fertilization rate $(p=0.004)$ for the independent female overweight / obesity group. The available embryo rate $(p=0.026)$, fertilization rate $(p=0.010)$ and the normal fertilization rate $(p=0.003)$ in the combined male and female overweight / obese group are also significantly reduced.

The negative impact of female BMI on the outcome of ART assisted pregnancy is widely supported by most early researchers: most believe that it will significantly reduce the LBR of ART and increase the rate of ART abortion [25$27,35]$. This negative effect may be related to the adverse effects of increased female BMI on the quality of oocytes and/or embryos[38].The increasing BMI will also have a negative effect on the reproductive status before and after embryo development as well as a negative effect on the quality of oocytes and the endometrial environment[22]. Some scholars use the donor oocyte model to analyze the ART outcome of female obesity and the results show that obesity does not significantly affect the chance of embryo implantation or clinical pregnancy.Obesity also has no significant effect on abortion and LBR, and obesity may have no significant effect on the endometrial receptivity खbut it may affect the outcome of ART by affecting oocytes [39]. Recent studies have found that the total lipid content of follicular fluid (FF) in obese women increases, and the changes in FF transmit maternal signals to oocytes, leading to lipid toxicity, impaired oocyte maturation and early embryo loss[40-43]. Our study found that female overweight/obesity can reduce the fertilization rate and the number of available embryos for IVF-treated, which may be related to the production of immature oocytes caused by the increase of female BMI. A large cohort study showed that compared with normal weight, the overweight/obesity in couples, both independently and combined, will reduce the LBR of the IVF treated, but there is no significant statistical difference[35]. This is similar to our conclusion that compared with the normal weight group, one parter or both being overweight/obese would not affect the LBR, CPR and abortion rate for IVF results ( $p>0.05)$, but this is different from the previous research conclusions[25-27, 35].The reason may be that those research did not involve the IVF/ICSI stratification analysis. In order to draw more accurate conclusions, we excluded those couples with ICSI treated. In addition, we established an adjustment model which modulated the factors such as age, HCG daily sex hormone value, and the number of available embryos that affect the outcome of IVF. In order to reduce the potential impact of partners on ovarian function, we also excluded patients with fewer than 4 follicles. In order to reduce the impact of multiple transplant cycles on the VF results, we only managed the data of the first fresh transplant cycle. Nevertheless, our research still has some limitations. Due to the unavailability of relative data from other IVF centers in China, the research data is just limited to our research center. Due to the limitedness of effort and time, we did not investigate the influence of overweight and obesity between male and female on IVF outcomes.

There has been a controversy as to whether male overweight/ obesity has an effect on fertility and ART outcome. Some scholars suggested that male overweight/obesity might affect sperm count and cause infertility[42]. A large observational study showed that male BMI might have a greater impact on embryo quality and IVF outcome than on semen parameters [36]. A recent meta-analysis showed that the increased male BMI could significantly reduce CPR and LBR of the ART $\triangle P \otimes 0.05 \rrbracket[44] \varangle$ which might further affect sperm DNA integrity by affecting changes in sex hormone parameters, The increased sperm DNA integrity damage levels are associated with lower CPR and higher 
abortion rates during IVF and ICSI cycles[45]. Other scholars hold different views: they believe that male BMI is not

related to sperm parameters, semen volume, motility or morphology [36, 46-49], and an increase in male BMI could hardly have a negative impact on CPR and LBR undergoing IVF or ICSI[28,50]. Our investigation reveals that, compared with the normal BMI group, the increased male BMI had no significant influence in the CPR \adjusted OR 1.04, 95\% CI 0.91-1.19凶and LBR囚adjusted OR 1.08, 95\% Cl 0.95-1.23囚of couples treated with treated ( $p>0.05)$. An increased male BMI will significantly reduce the cleavage rate $(p=0.019)$, and the increase of the combined female's BMI could significantly reduce the available embryo rate, the fertilization rate, and the normal fertilization rate $(p<0.05)$. It is still unclear whether the male BMI has an influence on the embryo quality and fertilization rate. It is also not clarified whether the male BMI is related to the increase of sperm DNA integrity damage and the impact of sperm DNA integrity which can further decrease the embryo quality and fertilization rate.

\section{Conclusions}

In summary, we found that overweight/obesity has an impact on IVF outcomes and there exists gender differences. Overweight/obese women seem to have a greater impact on IVF outcomes. In addition, the combined overweight/obesity of men and women has a greater impact on IVF outcomes than a single overweight/obese couple. As a result, the increased BMI is a risk factor for LBR and CPR, but there is not a significant difference when compared with the IVF results of the normal BMI. Even so, before the couples with increased BMI are going to be treated with IVF, it is better to recommend them to lose weight to the normal index to prevent the potential negative impact of overweight/obesity on the adverse outcome of IVF. The future research are suggested to obtain more data from other IVF centers in China and try to explore the mechanism of BMI's influence on the embryo quality and fertilization rate.

\section{Declarations}

\section{Acknowledgments}

The authors thank all of medical staffs in the The First Affiliated Hospital of Xi'an Jiao Tong University and Reproductive Center of Northwest Women's and Children's Hospital for recording all the data in this study through the years.

\section{Authors' contributions}

$\mathrm{XL}$, JHS and JZS contributed to the conception and design. XXcontributed to statistical analyzing and article writing. ZZ contributed to revising the article. JPXcontributed to revising

the article critically for important intellectual content. The authors read and approved the final version of the manuscript.

\section{Funding}

This work was supported by the Chinese Medical Association Clinical Medical Research Project - Reproductive Medicine Young Physician Research and Development Project (contracts 17020120681).

\section{Availability of data and materials}


The datasets used and analyzed during the current study are available from the corresponding author on reasonable request.

\section{Ethics approval and consent to participate}

This study was performed in accordance with guidelines outlined in the Declaration of Helsinki. All methods and information collection protocols were approved by the institutional review board of Northwest Women's and Children's Hospital, China XBFNLL (2019) 009. Our research has obtained the waiver from institutional review board for the medical record review for selective variable analysis in Reproductive Center of Northwest Women's and Children's Hospital.

\section{Consent for publication}

Not applicable.

\section{Competing interests}

The authors declare that they have no competing interests.

\section{Author details}

${ }^{1}$ The First Affiliated Hospital of Xi'an Jiao Tong University, Xi'an, Shaanxi 710061هChina.

${ }^{2}$ Reproductive Center of Northwest Women's and Children's Hospital, Xi'an, Shaanxi 710061هChina.

\section{References}

1. Kaidar-Person O, Bar-Sela G, Person B: The Two Major Epidemics of the Twenty-First Century: Obesity and Cancer. Obesity Surgery 2011, 21(11):1792-1797.

2. Nguyen DM, Elserag HB: The epidemiology of obesity. European Surgery 2010, 39(1):1.

3. Popkin BM, Adair LS, Wen NS: Global nutrition transition and the pandemic of obesity in developing countries. Nutrition Reviews 2012(1):3-21.

4. Wang Z, Hao G, Wang X, Chen Z, Zhang L, Guo M, Tian Y, Shao L, Zhu M: [Current prevalence rates of overweight, obesity, central obesity, and related cardiovascular risk factors that clustered among middle-aged population of China]. Zhonghua liu xing bing xue za zhi = Zhonghua liuxingbingxue zazhi 2014, 35(4):354.

5. Andegiorgish AK, Wang J, Zhang X, Liu X, Zhu H: Prevalence of overweight, obesity, and associated risk factors among school children and adolescents in Tianjin, China. European Journal of Pediatrics 2012, 171(4):697-703.

6. Fang C, Liang Y: Social disparities in body mass index (BMI) trajectories among Chinese adults in 19912011. International Journal for Equity in Health 2017, 16(1):146.

7. Zajacova A, Huzurbazar S, Greenwood M, Nguyen H: Long-Term BMI Trajectories and Health in Older Adults: Hierarchical Clustering of Functional Curves. Journal of Aging \& Health 2015:1443.

8. Collaboration NRF: Trends in adult body-mass index in 200 countries from 1975 to 2014: a pooled analysis of 1698 population-based measurement studies with $19 \cdot 2$ million participants. Lancet 2020, 2016ه387ه10026 邓:1377-1396区. 
9. M.M. Bossuyt3 Fulco van der Veen2 JWvdSPSMJCEJDFHPGAHJMBGJEOP, Mol27 BWJ: Obesity affects spontaneous pregnancy chances in subfertile, ovulatory women. Human Reproduction 2008, 23(2):324-328.

10. Women's NCCf, Health Cs: Fertility: assessment and treatment for people with fertility problems. Rcog Press 2013, 1(4):21 - 28.

11. Rajeshwari S, L MS, M BLG: Couples' body composition and time-to-pregnancy. Human Reproduction 2017(3):1.

12. Andersson AM, J?Rgensen N, Main KM, Toppari J, Meyts RD, Leffers H, Juul A, Jensen TK, Skakkeb?K NE: Adverse trends in male reproductive health: we may have reached a crucial 'tipping point'.

13. Katib A: Mechanisms linking obesity to male infertility. Central European Journal of Urology 2015, 68(1):7985.

14. Vilarino FL, Christofolini DM, Rodrigues D, De Souza AMB, Christofolini J, Bianco B, Barbosa CP: Body mass index and fertility: is there a correlation with human reproduction outcomes? Gynecological Endocrinology 2011, 27(4):232-236.

15. L. EM, Sungduk K, Zhen C, Rajeshwari S, F. SE, M. BLG: The relationship between male BMI and waist circumference on semen quality: data from the LIFE study. Human Reproduction 2014(2):193-200.

16. Chih-Wei T, Chin-Yu L, Yu-Ching C, Tai-Lung C, Shih-Chang C, Chien-Yeh H: Exploration of the association

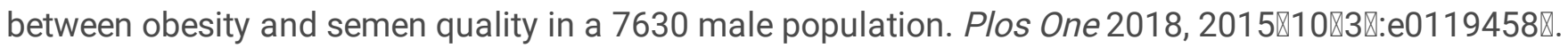

17. Faddy MJ, Gosden MD, Gosden RG: A demographic projection of the contribution of assisted reproductive technologies to world population growth. Reproductive Biomedicine Online 2018:S1472648318300397.

18. Rittenberg V, Seshadri S, Sunkara SK, Sobaleva S, Oteng-Ntim E, El-Toukhy T: Effect of body mass index on IVF treatment outcome: an updated systematic review and meta-analysis. Reprod Biomed Online 2011, 23(4):421-439.

19. Luke B, Brown MB, Stern JE, Missmer SA, Fujimoto VY, Leach R, Group SW: Female obesity adversely affects assisted reproductive technology (ART) pregnancy and live birth rates. Hum Reprod 2011, 26(1):245-252.

20. Pinborg A, Gaarslev C, Hougaard CO, Nyboe Andersen A, Andersen PK, Boivin J, Schmidt L: Influence of female bodyweight on IVF outcome: a longitudinal multicentre cohort study of 487 infertile couples. Reprod Biomed Online 2011, 23(4):490-499.

21. Supramaniam PR, Mittal M, McVeigh E, Lim LN: The correlation between raised body mass index and assisted reproductive treatment outcomes: a systematic review and meta-analysis of the evidence. Reprod Health 2018, 15(1):34.

22. Ferlitsch K, Sator MO, Gruber DM, Rücklinger E, Gruber CJ, Huber JC: Body Mass Index, Follicle-Stimulating Hormone and Their Predictive Value in In Vitro Fertilization. Journal of Assisted Reproduction \& Genetics 2004, 21(12):431-436.

23. Lintsen, A. ME: Effects of subfertility cause, smoking and body weight on the success rate of IVF. Human Reproduction 2005, 20(7):1867.

24. Wang JX, Davies M, Norman RJ: Body mass and probability of pregnancy during assisted reproduction treatment: retrospective study. Bmj 2019, 2000®321ه7272『(7272):1320-1321》.

25. Wang L, Yin M, Liu Y, Chen Q, Wang Y, Ai A, Fu Y, Yan Z, Jin W, Long H: Effect of Frozen Embryo Transfer and Progestin-primed Ovary Stimulation on IVF outcomes in women with high body mass index. Scientific Reports 2017, 7(1):7447. 
26. Luke B: Adverse effects of female obesity and interaction with race on reproductive potential. Fertil Steril 2017, 107(4):868-877.

27. Luke B, Brown MB, Stern JE, Missmer SA, Fujimoto VY, Leach R: Racial and ethnic disparities in assisted reproductive technology pregnancy and live birth rates within body mass index categories. Fertil Steril 2011, 95(5):1661-1666.

28. Schliep KC, Mumford SL, Ahrens KA, Hotaling JM, Carrell DT, Link M, Hinkle SN, Kissell K, Porucznik CA, Hammoud AO: Effect of male and female body mass index on pregnancy and live birth success after in vitro fertilization. Fertil Steril 2015, 103(2):388-395.

29. Thomsen L, Humaidan P, Bungum L, Bungum M: The impact of male overweight on semen quality and outcome of assisted reproduction. Asian J Androl 2014, 16(5):749-754.

30. Braga DP, Halpern G, Figueira Rde C, Setti AS, laconelli A, Jr., Borges E, Jr.: Food intake and social habits in male patients and its relationship to intracytoplasmic sperm injection outcomes. Fertil Steril 2012, 97(1):5359.

31. Bakos HW, Henshaw RC, Mitchell M, Lane M: Paternal body mass index is associated with decreased blastocyst development and reduced live birth rates following assisted reproductive technology. Fertil Steril 2011, 95(5):1700-1704.

32. Umul M, Kose SA, Bilen E, Altuncu AG, Oksay T, Guney M: Effect of increasing paternal body mass index on pregnancy and live birth rates in couples undergoing intracytoplasmic sperm injection. Andrologia 2015, 47(3):360-364.

33. Merhi ZO, Keltz J, Zapantis A, Younger J, Berger D, Lieman HJ, Jindal SK, Polotsky AJ: Male adiposity impairs clinical pregnancy rate by in vitro fertilization without affecting day 3 embryo quality. Obesity (Silver Spring) 2013, 21(8):1608-1612.

34. Keltz J, Zapantis A, Jindal SK, Lieman HJ, Santoro N, Polotsky AJ: Overweight men: clinical pregnancy after ART is decreased in IVF but not in ICSI cycles. J Assist Reprod Genet 2010, 27(9-10):539-544.

35. Petersen GL, Schmidt L, Pinborg A, Kamper-Jorgensen M: The influence of female and male body mass index on live births after assisted reproductive technology treatment: a nationwide register-based cohort study. Fertil Steril 2013, 99(6):1654-1662.

36. Anifandis G, Dafopoulos K, Messini Cl, Polyzos N, Messinis IE: The BMI of men and not sperm parameters impact on embryo quality and the IVF outcome. Andrology 2013, 1(1):85-89.

37. Paasch U, Grunewald S, Kratzsch J, Glander HJ: Obesity and age affect male fertility potential. Fertil Steril 2010, 94(7):2898-2901.

38. Robker RL: Evidence that obesity alters the quality of oocytes and embryos. Pathophysiology 2008, 15(2):115-121.

39. Jungheim ES, Schon SB, Schulte MB, DeUgarte DA, Fowler SA, Tuuli MG: IVF outcomes in obese donor oocyte recipients: a systematic review and meta-analysis. Hum Reprod 2013, 28(10):2720-2727.

40. Valckx SD, De Pauw I, De Neubourg D, Inion I, Berth M, Fransen E, Bols PE, Leroy JL: BMI-related metabolic composition of the follicular fluid of women undergoing assisted reproductive treatment and the consequences for oocyte and embryo quality. Hum Reprod 2012, 27(12):3531-3539.

41. Wu LL, Dunning KR, Yang X, Russell DL, Lane M, Norman RJ, Robker RL: High-fat diet causes lipotoxicity responses in cumulus-oocyte complexes and decreased fertilization rates. Endocrinology 2010, 151(11):54385445. 
42. Yang X, Wu LL, Chura LR, Liang X, Lane M, Norman RJ, Robker RL: Exposure to lipid-rich follicular fluid is associated with endoplasmic reticulum stress and impaired oocyte maturation in cumulus-oocyte complexes. Fertil Steril 2012, 97(6):1438-1443.

43. Batushansky A, Zacharia A, Shehadeh A, Bruck-Haimson R, Saidemberg D, Kogan NM, Thomas Mannully C, Herzberg S, Ben-Meir A, Moussaieff A: A Shift in Glycerolipid Metabolism Defines the Follicular Fluid of IVF Patients with Unexplained Infertility. Biomolecules 2020, 10(8).

44. Mushtaq R, Pundir J, Achilli C, Naji O, Khalaf Y, El-Toukhy T: Effect of male body mass index on assisted reproduction treatment outcome: an updated systematic review and meta-analysis. Reprod Biomed Online 2018, 36(4):459-471.

45. Zhao J, Zhang Q, Wang Y, Li Y: Whether sperm deoxyribonucleic acid fragmentation has an effect on pregnancy and miscarriage after in vitro fertilization/intracytoplasmic sperm injection: a systematic review and meta-analysis. Fertil Steril 2014, 102(4):998-1005 e1008.

46. Martini AC, Tissera A, Estofan D, Molina RI, Mangeaud A, de Cuneo MF, Ruiz RD: Overweight and seminal quality: a study of 794 patients. Fertil Steril 2010, 94(5):1739-1743.

47. MacDonald AA, Herbison GP, Showell M, Farquhar CM: The impact of body mass index on semen parameters and reproductive hormones in human males: a systematic review with meta-analysis. Hum Reprod Update 2010, 16(3):293-311.

48. Chavarro JE, Toth TL, Wright DL, Meeker JD, Hauser R: Body mass index in relation to semen quality, sperm DNA integrity, and serum reproductive hormone levels among men attending an infertility clinic. Fertil Steril 2010, 93(7):2222-2231.

49. Teerds KJ, de Rooij DG, Keijer J: Functional relationship between obesity and male reproduction: from humans to animal models. Hum Reprod Update 2011, 17(5):667-683.

50. Le W, Su SH, Shi LH, Zhang JF, Wu DL: Effect of male body mass index on clinical outcomes following assisted reproductive technology: a meta-analysis. Andrologia 2016, 48(4):406-424.

\section{Tables}

Table 1 Demographics of study samples by male and female BMI status. 


\begin{tabular}{|c|c|c|c|c|c|}
\hline variables & $\begin{array}{l}\text { Group } 1 \\
(\mathrm{~N}=3413)\end{array}$ & Group 2 (N=1437) & $\begin{array}{l}\text { Group } 3 \\
(\mathrm{~N}=4283)\end{array}$ & Group $4(\mathrm{~N}=2176)$ & $\begin{array}{l}\mathrm{P}- \\
\text { trend }\end{array}$ \\
\hline $\begin{array}{l}\text { Male age } \\
\text { (years) }\end{array}$ & $30.21 \pm 3.06$ & $30.28 \pm 2.97$ & $30.57 \pm 2.99 *$ & $30.58 \pm 2.99 *$ & $<0.000$ \\
\hline $\begin{array}{l}\text { Female age } \\
\text { (years) }\end{array}$ & $29.07 \pm 2.93$ & $28.97 \pm 3.06$ & $29.48 \pm 2.95^{\star}$ & $29.36 \pm 2.99 *$ & $<0.000$ \\
\hline $\begin{array}{l}\text { Endometrium } \\
\text { thickness } \\
(\mathrm{mm})\end{array}$ & $11.67 \pm 2.31$ & $11.86 \pm 4.02^{\star}$ & $11.68 \pm 2.73$ & $11.77 \pm 3.05$ & 0.555 \\
\hline $\begin{array}{l}\text { Year of } \\
\text { infertility } \\
\text { (years) }\end{array}$ & $3.17 \pm 1.99$ & $3.48 \pm 2.06 *$ & $3.19 \pm 1.99$ & $3.60 \pm 2.12^{\star}$ & $<0.000$ \\
\hline $\begin{array}{l}\text { E2 on HCG } \\
\text { day }(\mathrm{mlU} / \mathrm{ml})\end{array}$ & $4814.74 \pm 2764.14$ & $3761.31 \pm 2403.16 *$ & $4707.29 \pm 2703.74$ & $3815.21 \pm 2451.30 *$ & $<0.000$ \\
\hline $\begin{array}{l}\text { FSH on HCG } \\
\text { day }(\mathrm{mlU} / \mathrm{ml})\end{array}$ & $18.28 \pm 9.31$ & $14.62 \pm 7.73^{\star}$ & $17.79 \pm 8.34^{\star}$ & $14.53 \pm 6.30^{*}$ & $<0.000$ \\
\hline $\begin{array}{l}\text { P on HCG } \\
\text { day }(\mathrm{mlU} / \mathrm{ml})\end{array}$ & $1.40 \pm 0.79$ & $1.21 \pm 0.75^{\star}$ & $1.37 \pm 0.71$ & $1.19 \pm 0.69 *$ & $<0.000$ \\
\hline $\begin{array}{l}\text { LH on HCG } \\
\text { day }(\mathrm{ng} / \mathrm{ml})\end{array}$ & $1.80 \pm 1.31$ & $1.60 \pm 1.52 *$ & $1.87 \pm 1.50 *$ & $1.62 \pm 1.31^{\star}$ & 0.052 \\
\hline $\begin{array}{l}\text { Number of } \\
\text { available } \\
\text { Embryos }\end{array}$ & $6.41 \pm 3.88$ & $6.02 \pm 3.73^{\star}$ & $6.36 \pm 3.77$ & $6.03 \pm 3.87 *$ & 0.011 \\
\hline $\begin{array}{l}\text { Number of } \\
\text { high-quality } \\
\text { embryos }\end{array}$ & $3.98 \pm 3.13$ & $3.72 \pm 3.03^{\star}$ & $3.98 \pm 3.12$ & $3.77 \pm 3.21$ * & 0.161 \\
\hline $\begin{array}{l}\text { Left } \\
\text { testicular } \\
\text { volume (ml) }\end{array}$ & $14.28 \pm 2.00$ & $14.24 \pm 1.91$ & $14.70 \pm 2.25^{\star}$ & $14.77 \pm 2.42^{\star}$ & $<0.000$ \\
\hline $\begin{array}{l}\text { Right } \\
\text { testicular } \\
\text { volume (ml) }\end{array}$ & $14.30 \pm 1.98$ & $14.29 \pm 1.84$ & $14.75 \pm 2.23^{*}$ & $14.75 \pm 2.43^{\star}$ & $<0.000$ \\
\hline
\end{tabular}

Group 1: male $18.5 \leq \mathrm{BMI}<24 \mathrm{~kg} / \mathrm{m}^{2}$ and female $18.5 \leq \mathrm{BMI}<24 \mathrm{~kg} / \mathrm{m}^{2}$; group 2: female $\mathrm{BMI} \geq 24 \mathrm{~kg} / \mathrm{m}^{2}$ and male $18.5 \leq \mathrm{BMl}<24 \mathrm{~kg} / \mathrm{m}^{2} ;$ group 3 : female $18.5 \leq \mathrm{BMl}<24 \mathrm{~kg} / \mathrm{m}^{2}$ and male BMI $\geq 24 \mathrm{~kg} / \mathrm{m}^{2} ;$ group 4 : female BMI $\geq 24$ $\mathrm{kg} / \mathrm{m}^{2}$ and male $\mathrm{BMl} \geq 24 \mathrm{~kg} / \mathrm{m}^{2}$

The values are presented as mean ( $\pm \mathrm{SD})$, compared using linear regression (group 1 as reference).

* $P<0.05$ was considered statistically significant.

Table 2 Comparison of clinical outcomes from IVF treatment between male and female BMI status. 


\begin{tabular}{|c|c|c|c|c|c|}
\hline variables & Group $1(\mathrm{~N}=3413)$ & $\begin{array}{l}\text { Group 2 } \\
(\mathrm{N}=1437)\end{array}$ & $\begin{array}{l}\text { Group } 3 \\
(\mathrm{~N}=4283)\end{array}$ & $\begin{array}{l}\text { Group } 4 \\
(\mathrm{~N}=2176)\end{array}$ & $\begin{array}{l}\mathrm{P}- \\
\text { trend }\end{array}$ \\
\hline $\begin{array}{l}\text { Available embryo rate } \\
(\%)\end{array}$ & $64.62 \pm 22.89$ & $63.61 \pm 23.73$ & $64.67 \pm 23.02$ & $63.40 \pm 23.91$ & 0.235 \\
\hline $\begin{array}{l}\text { High quality embryo } \\
\text { rate (\%) }\end{array}$ & $39.80 \pm 25.24$ & $38.90 \pm 25.99$ & $40.30 \pm 25.60$ & $39.28 \pm 26.35$ & 0.996 \\
\hline Fertilization rate (\%) & $83.71 \pm 18.08$ & $82.05 \pm 18.45^{\star}$ & $83.94 \pm 17.48$ & $82.34 \pm 18.81$ * & 0.284 \\
\hline $\begin{array}{l}\text { Normal fertilization } \\
\text { rate (\%) }\end{array}$ & $62.46 \pm 20.19$ & $60.41 \pm 20.31 *$ & $61.95 \pm 19.81$ & $60.82 \pm 21.03^{*}$ & 0.084 \\
\hline Cleavage rate (\%) & $98.39 \pm 6.14$ & $98.43 \pm 5.84$ & $98.63 \pm 5.24$ & $98.39 \pm 5.57$ & 0.430 \\
\hline Blastocyst rate (\%) & $31.20 \pm 37.22$ & $32.89 \pm 36.79$ & $33.82 \pm 37.32^{\star}$ & $32.61 \pm 37.16$ & 0.053 \\
\hline Implantation rate (\%) & $86.21 \pm 26.93$ & $86.54 \pm 26.62$ & $87.92 \pm 29.80$ & $87.13 \pm 27.48$ & 0.216 \\
\hline $\begin{array}{l}\text { Clinical pregnancy }(\mathrm{n}, \\
\%)\end{array}$ & $\begin{array}{l}1274 / 1947 \\
(65.43)\end{array}$ & $\begin{array}{l}606 / 894 \\
(67.79)\end{array}$ & $\begin{array}{l}1638 / 2461 \\
(66.56)\end{array}$ & $\begin{array}{l}891 / 1313 \\
(67.86)\end{array}$ & 0.212 \\
\hline Abortion (n, \%) & $71 / 1274(5.57)$ & $41 / 606(6.75)$ & $80 / 1638(4.88)$ & $56 / 891(6.29)$ & 0.985 \\
\hline Live birth (n, \%) & $1096 / 1947(56.29)$ & $\begin{array}{l}516 / 894 \\
(57.72)\end{array}$ & $\begin{array}{l}1438 / 2461 \\
(58.43)\end{array}$ & $\begin{array}{l}753 / 1313 \\
(57.35)\end{array}$ & 0.338 \\
\hline
\end{tabular}

The values are presented as mean $( \pm S D)$ and proportion, compared using linear regression and logistic regression respectively (group 1 as reference).

* $\mathrm{P}<0.05$ was considered statistically significant.

Table 3. The association of BMI status and IVF treatment outcomes. 


\begin{tabular}{|c|c|c|c|c|}
\hline & \multicolumn{2}{|l|}{ Model 1} & \multicolumn{2}{|l|}{ Model 2} \\
\hline & b-coefficient (95\% Cl) & P-value & b-coefficient (95\% Cl) & P-value \\
\hline \multicolumn{5}{|c|}{ Available embryo rate (\%) } \\
\hline Group 1 & Referent & & Referent & \\
\hline Group 2 & $-1.00(-2.44,0.43)$ & 0.171 & $-1.14(-2.42,0.14)$ & 0.082 \\
\hline Group 3 & $0.00(-1.05,1.05)$ & 0.996 & $-0.46(-1.38,0.46)$ & 0.329 \\
\hline Group 4 & $-1.26(-2.51,-0.00)$ & 0.050 & $-1.29(-2.42,-0.16)$ & 0.026 \\
\hline $\mathrm{P}_{\text {-trend }}$ & $-0.25(-0.64,0.13)$ & 0.200 & $-0.32(-0.66,0.02)$ & 0.069 \\
\hline \multicolumn{5}{|c|}{ High quality embryo rate (\%) } \\
\hline Group 1 & Referent & & Referent & \\
\hline Group 2 & $-0.90(-2.48,0.69)$ & 0.269 & $-0.60(-2.16,0.95)$ & 0.447 \\
\hline Group 3 & $0.49(-0.67,1.65)$ & 0.412 & $0.17(-0.95,1.29)$ & 0.770 \\
\hline Group 4 & $-0.52(-1.91,0.87)$ & 0.461 & $-0.87(-2.24,0.51)$ & 0.217 \\
\hline$P_{\text {-trend }}$ & $-0.00(-0.43,0.43)$ & 0.990 & $-0.14(-0.56,0.28)$ & 0.512 \\
\hline \multicolumn{5}{|c|}{ Fertilization rate (\%) } \\
\hline Group 1 & Referent & & Referent & \\
\hline Group 2 & $-1.66(-3.10,-0.23)$ & 0.023 & $-1.56(-2.95,-0.16)$ & 0.029 \\
\hline Group 3 & $0.18(-0.87,1.23)$ & 0.736 & $-0.07(-1.07,0.93)$ & 0.893 \\
\hline Group 4 & $-1.40(-2.66,-0.15)$ & 0.028 & $-1.61(-2.84,-0.38)$ & 0.010 \\
\hline$P_{\text {-trend }}$ & $-0.23(-0.61,0.16)$ & 0.247 & $-0.30(-0.68,0.07)$ & 0.110 \\
\hline \multicolumn{5}{|c|}{ Normal fertilization rate (\%) } \\
\hline Group 1 & Referent & & Referent & \\
\hline Group 2 & $-2.06(-3.66,-0.45)$ & 0.012 & $-2.06(-3.47,-0.66)$ & 0.004 \\
\hline Group 3 & $-0.60(-1.77,0.57)$ & 0.315 & $-0.95(-1.96,0.06)$ & 0.066 \\
\hline Group 4 & $-1.72(-3.12,-0.31)$ & 0.006 & $-1.90(-3.14,-0.65)$ & 0.003 \\
\hline $\mathrm{P}_{\text {-trend }}$ & $-0.42(-0.85,0.02)$ & 0.060 & $-0.50(-0.88,-0.12)$ & 0.009 \\
\hline \multicolumn{5}{|c|}{ Cleavage rate (\%) } \\
\hline Group 1 & Referent & & Referent & \\
\hline Group 2 & $0.04(-0.31,0.39)$ & 0.832 & $0.06(-0.33,0.45)$ & 0.765 \\
\hline Group 3 & $0.24(-0.01,0.50)$ & 0.065 & $0.34(0.06,0.61)$ & 0.019 \\
\hline Group 4 & $0.00(-0.30,0.31)$ & 0.977 & $0.03(-0.32,0.37)$ & 0.878 \\
\hline
\end{tabular}




\begin{tabular}{|c|c|c|c|c|}
\hline$P_{\text {-trend }}$ & $0.04(-0.06,0.13)$ & 0.417 & $0.06(-0.04,0.17)$ & 0.243 \\
\hline \multicolumn{5}{|c|}{ Blastocyst rate (\%) } \\
\hline Group 1 & Referent & & Referent & \\
\hline Group 2 & $1.69(-0.93,4.31)$ & 0.206 & $1.25(-1.54,4.04)$ & 0.381 \\
\hline Group 3 & $2.47(0.57,4.38)$ & 0.011 & $1.58(-0.42,3.58)$ & 0.122 \\
\hline Group 4 & $1.30(-0.99,3.59)$ & 0.265 & $0.48(-1.99,2.95)$ & 0.703 \\
\hline$P_{\text {-trend }}$ & $0.64(-0.06,1.35)$ & 0.074 & $0.33(-0.42,1.08)$ & 0.392 \\
\hline \multicolumn{5}{|c|}{ Clinical pregnancy } \\
\hline Group 1 & Referent & & Referent & \\
\hline Group 2 & $1.11(0.94,1.32)$ & 0.214 & $1.02(0.85,1.23)$ & 0.850 \\
\hline Group 3 & $1.06(0.94,1.21)$ & 0.341 & $1.04(0.91,1.19)$ & 0.583 \\
\hline Group 4 & $1.12(0.97,1.31)$ & 0.122 & $1.09(0.92,1.29)$ & 0.299 \\
\hline$P_{\text {-trend }}$ & $1.03(0.99,1.08)$ & 0.160 & $1.03(0.98,1.08)$ & 0.305 \\
\hline \multicolumn{5}{|l|}{ Abortion } \\
\hline Group 1 & Referent & & Referent & \\
\hline Group 2 & $1.23(0.83,1.83)$ & 0.307 & $1.12(0.71,1.75)$ & 0.625 \\
\hline Group 3 & $0.84(0.61,1.17)$ & 0.310 & $0.84(0.59,1.20)$ & 0.341 \\
\hline Group 4 & $1.11(0.77,1.59)$ & 0.580 & $0.94(0.63,1.42)$ & 0.784 \\
\hline$P_{\text {-trend }}$ & $0.99(0.88,1.11)$ & 0.866 & $0.95(0.84,1.08)$ & 0.452 \\
\hline \multicolumn{5}{|l|}{ Live birth } \\
\hline Group 1 & Referent & & Referent & \\
\hline Group 2 & $1.06(0.90,1.25)$ & 0.467 & $1.01(0.85,1.21)$ & 0.902 \\
\hline Group 3 & $1.11(0.98,1.25)$ & 0.096 & $1.08(0.95,1.23)$ & 0.241 \\
\hline Group 4 & $1.06(0.92,1.22)$ & 0.454 & $1.03(0.88,1.21)$ & 0.683 \\
\hline $\mathrm{P}_{\text {-trend }}$ & $1.03(0.98,1.07)$ & 0.240 & $1.02(0.97,1.07)$ & 0.404 \\
\hline
\end{tabular}

Model 1 adjusted for female age and male age.

Model 2 adjusted for female age, male age, year of infertility, E2 on HCG day, FSH on HCG day, P on HCG day, LH on HCG day, number of available embryos, left testicular volume, and right testicular volume.

\section{Figures}




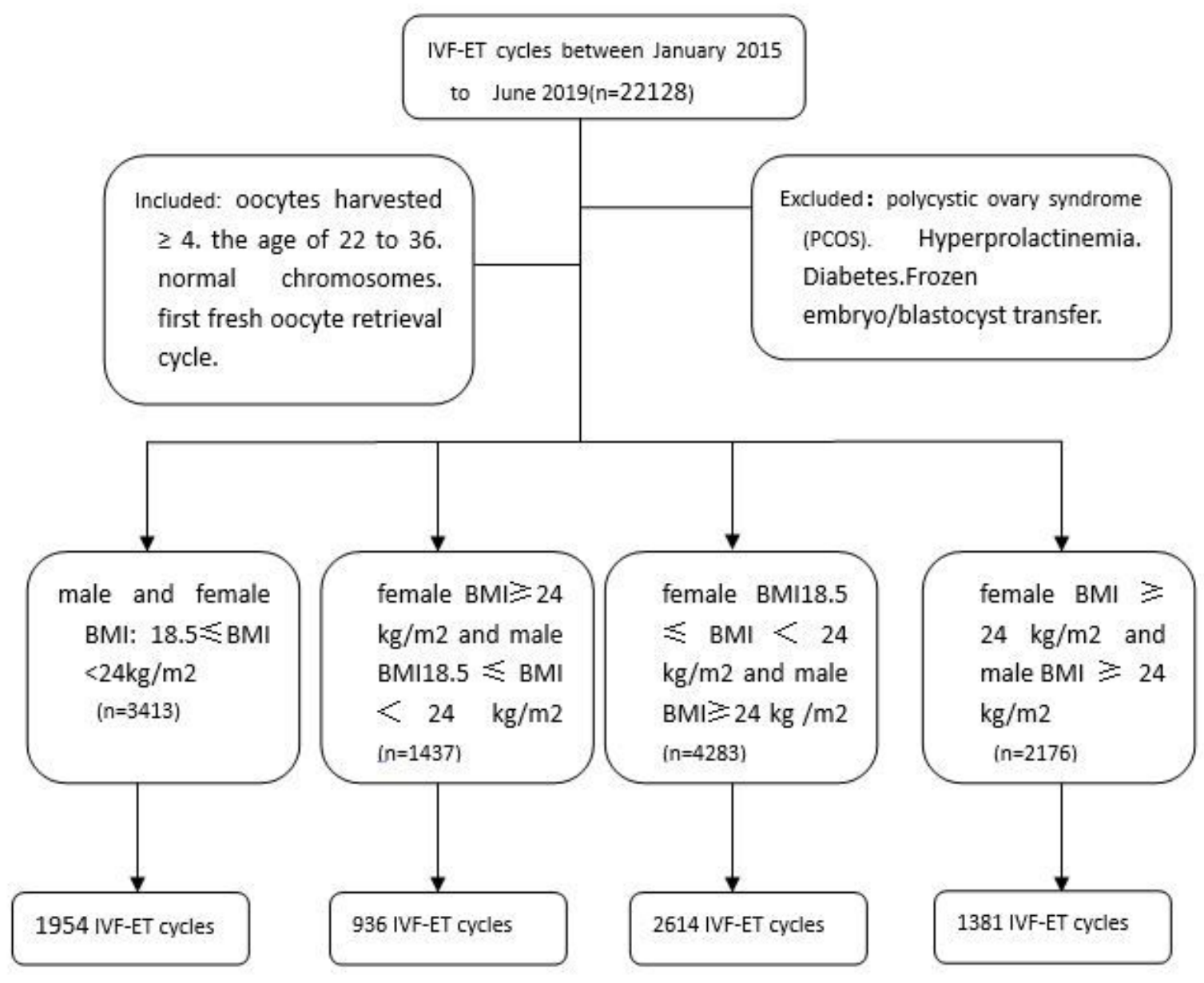

Figure 1

Flow-chart of the study cohort characteristics. 


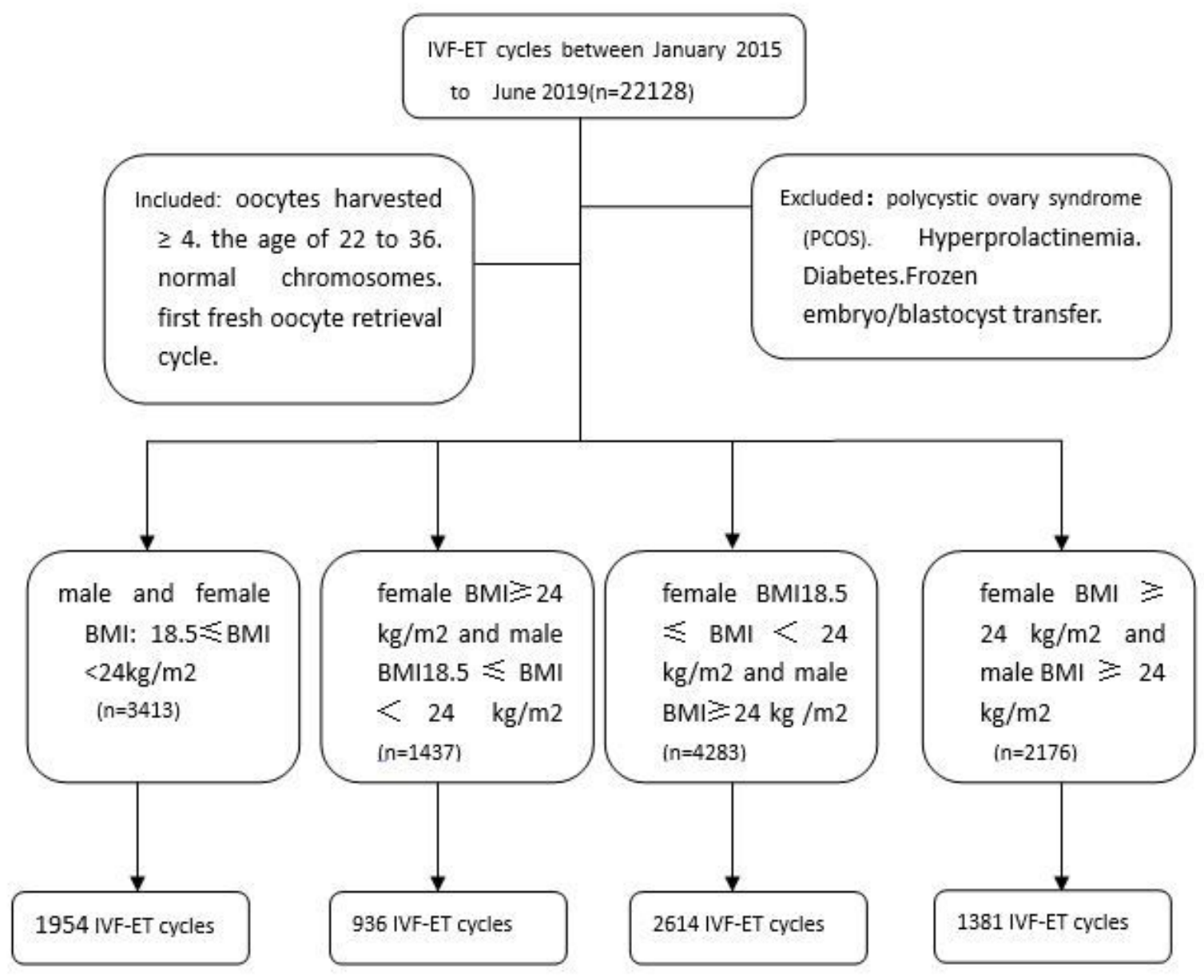

Figure 1

Flow-chart of the study cohort characteristics. 


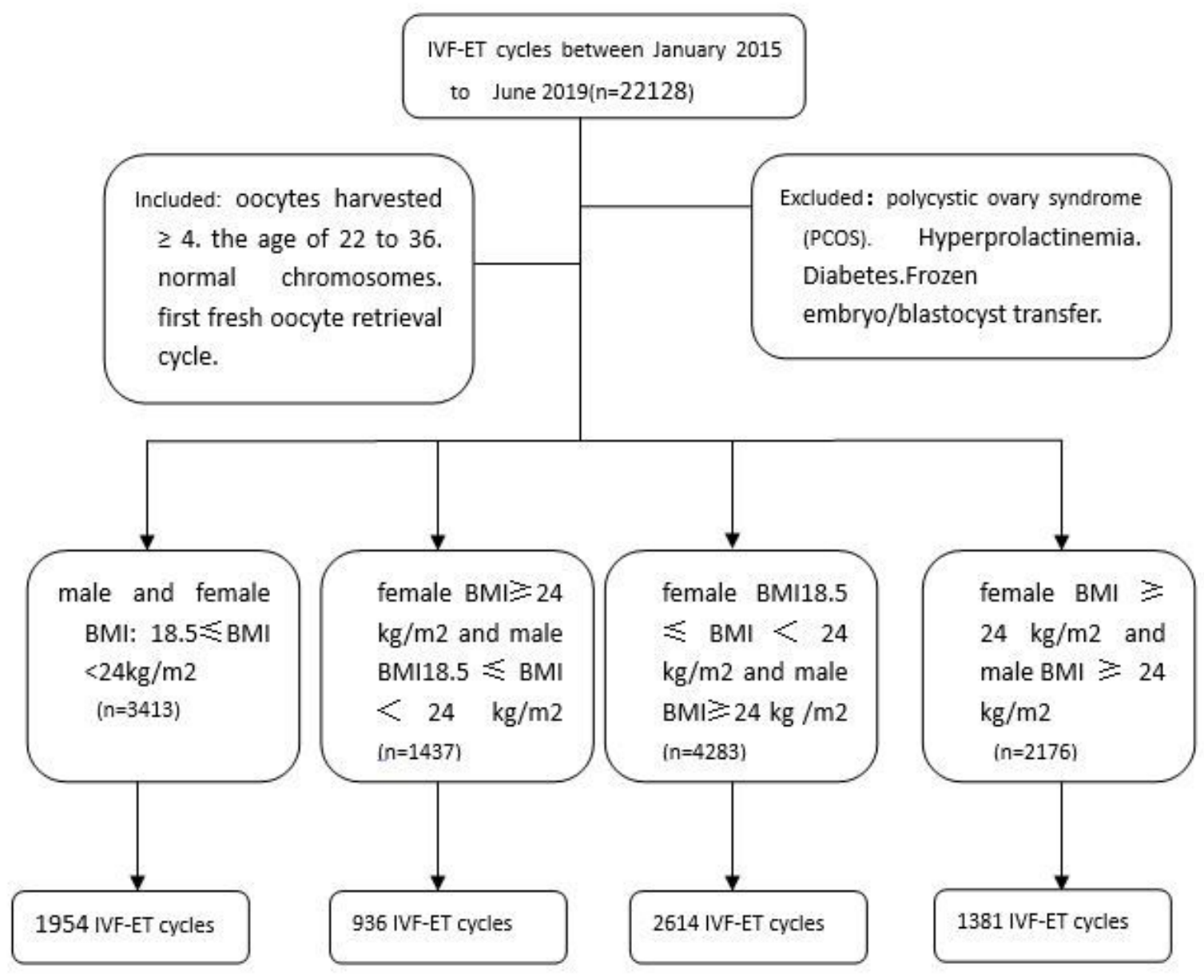

Figure 1

Flow-chart of the study cohort characteristics. 


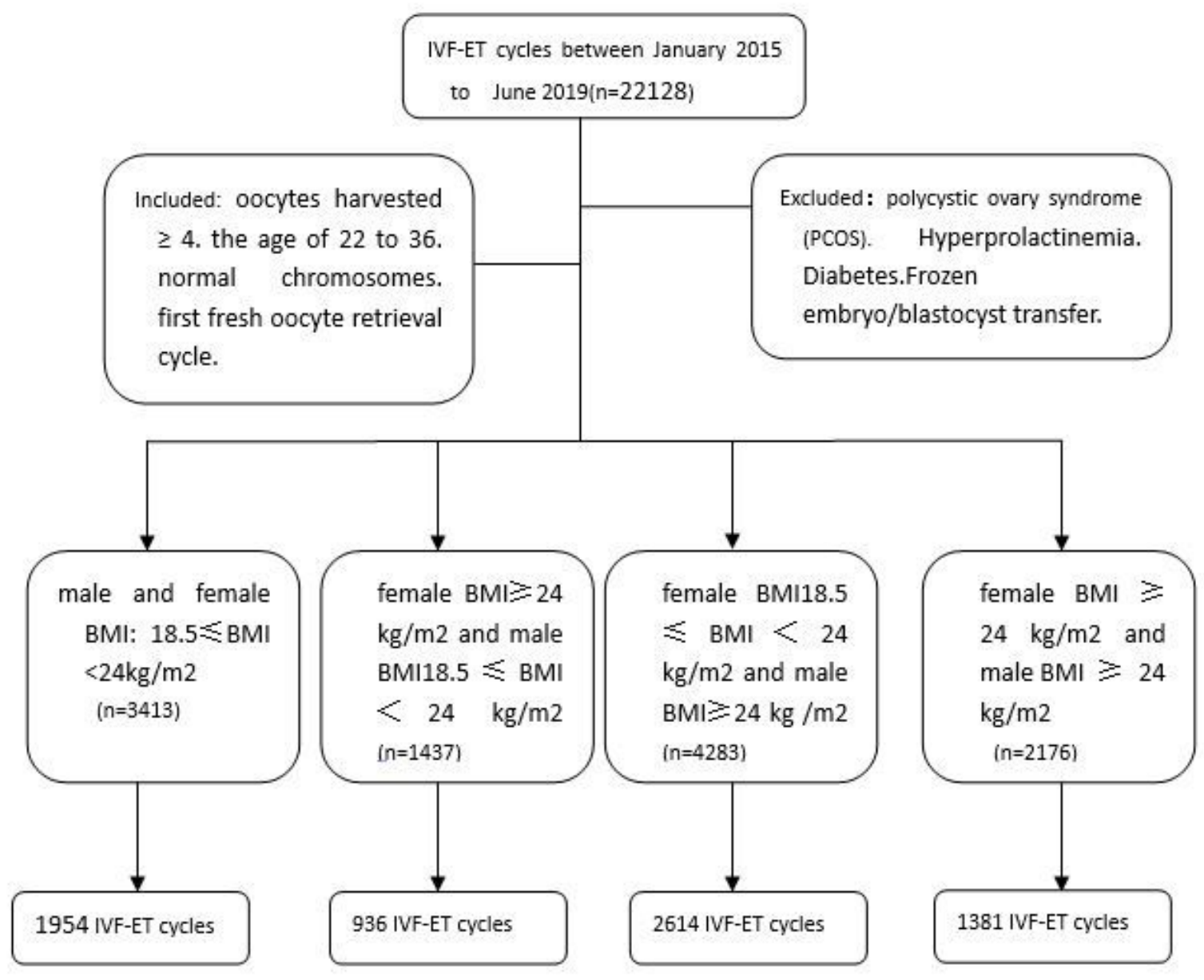

Figure 1

Flow-chart of the study cohort characteristics. 


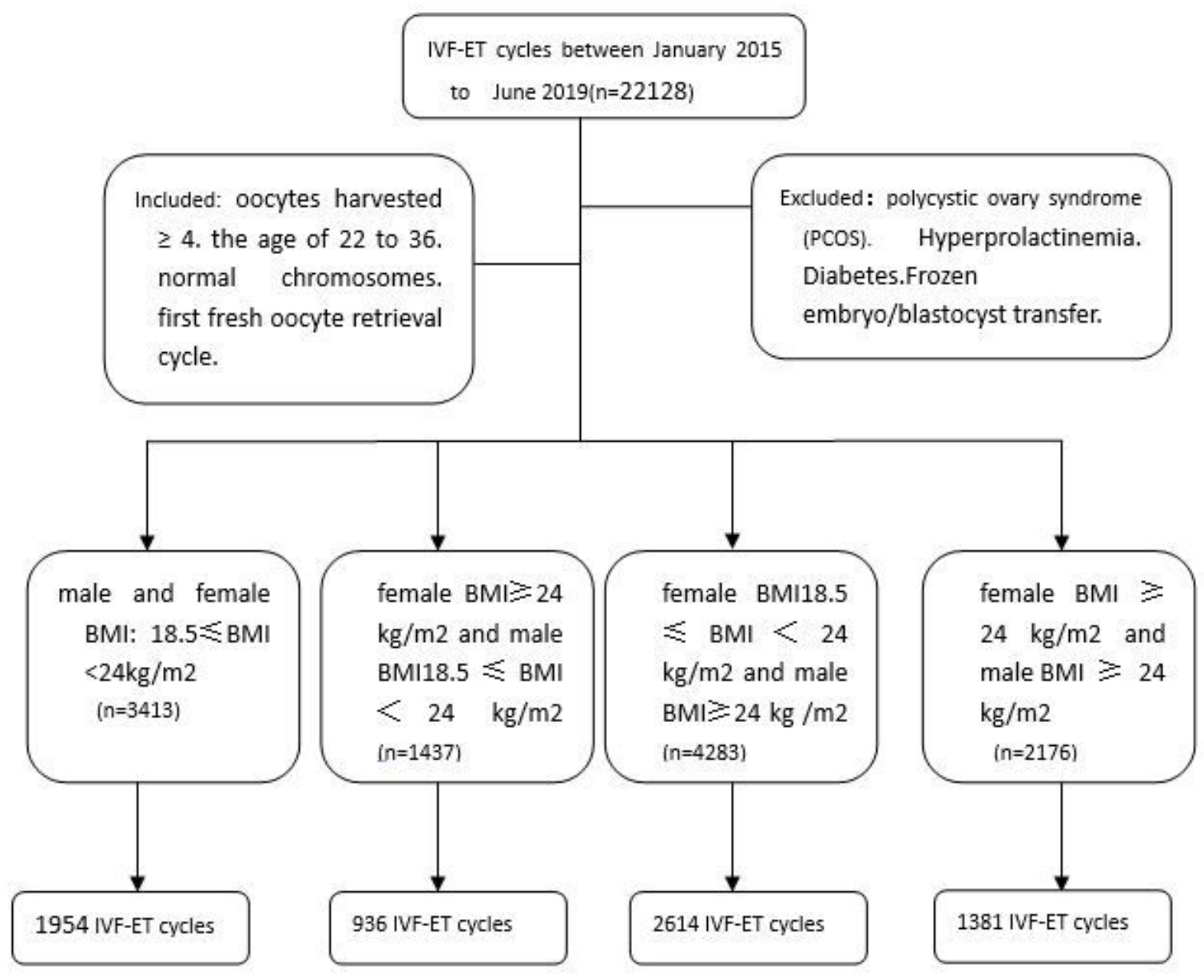

Figure 1

Flow-chart of the study cohort characteristics. 


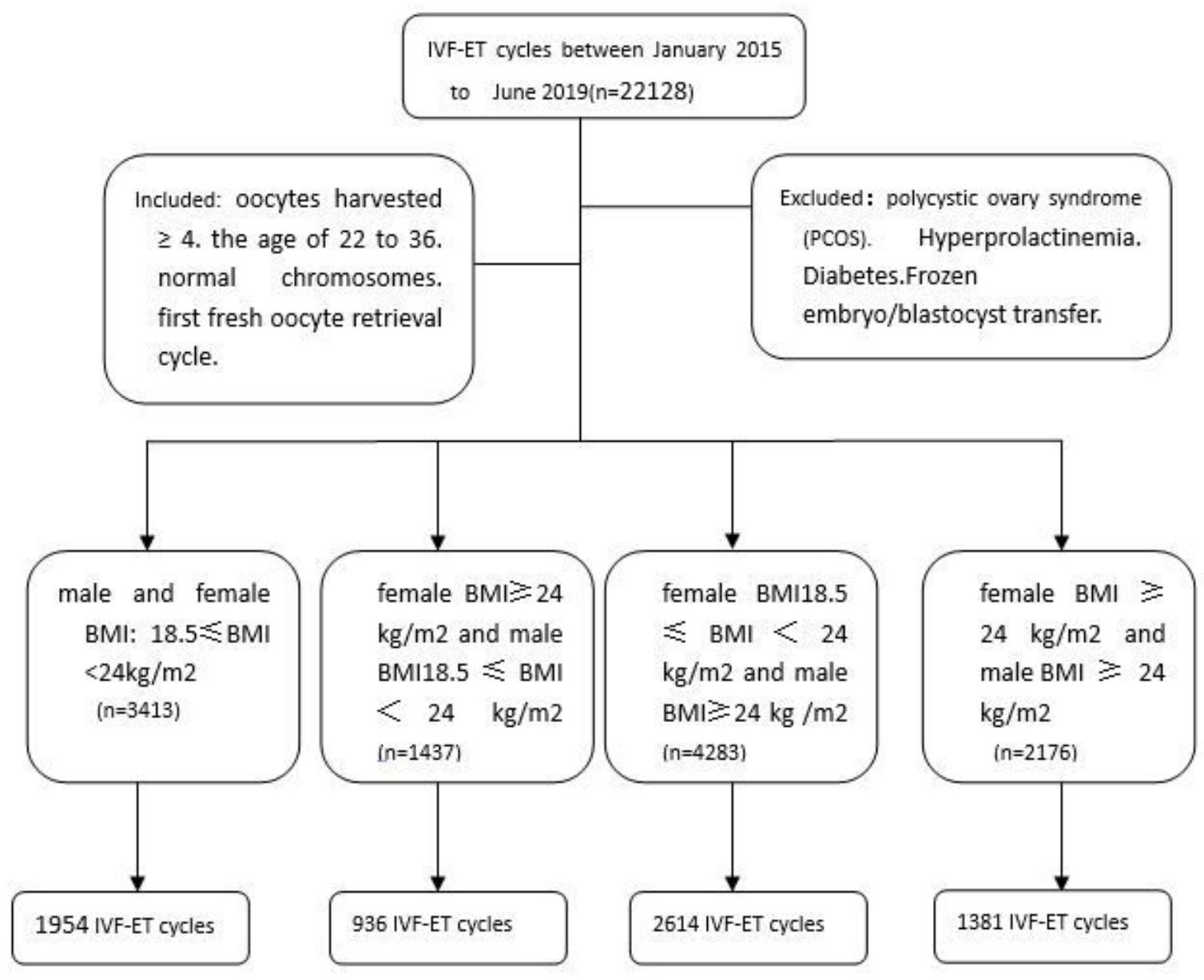

Figure 1

Flow-chart of the study cohort characteristics. 


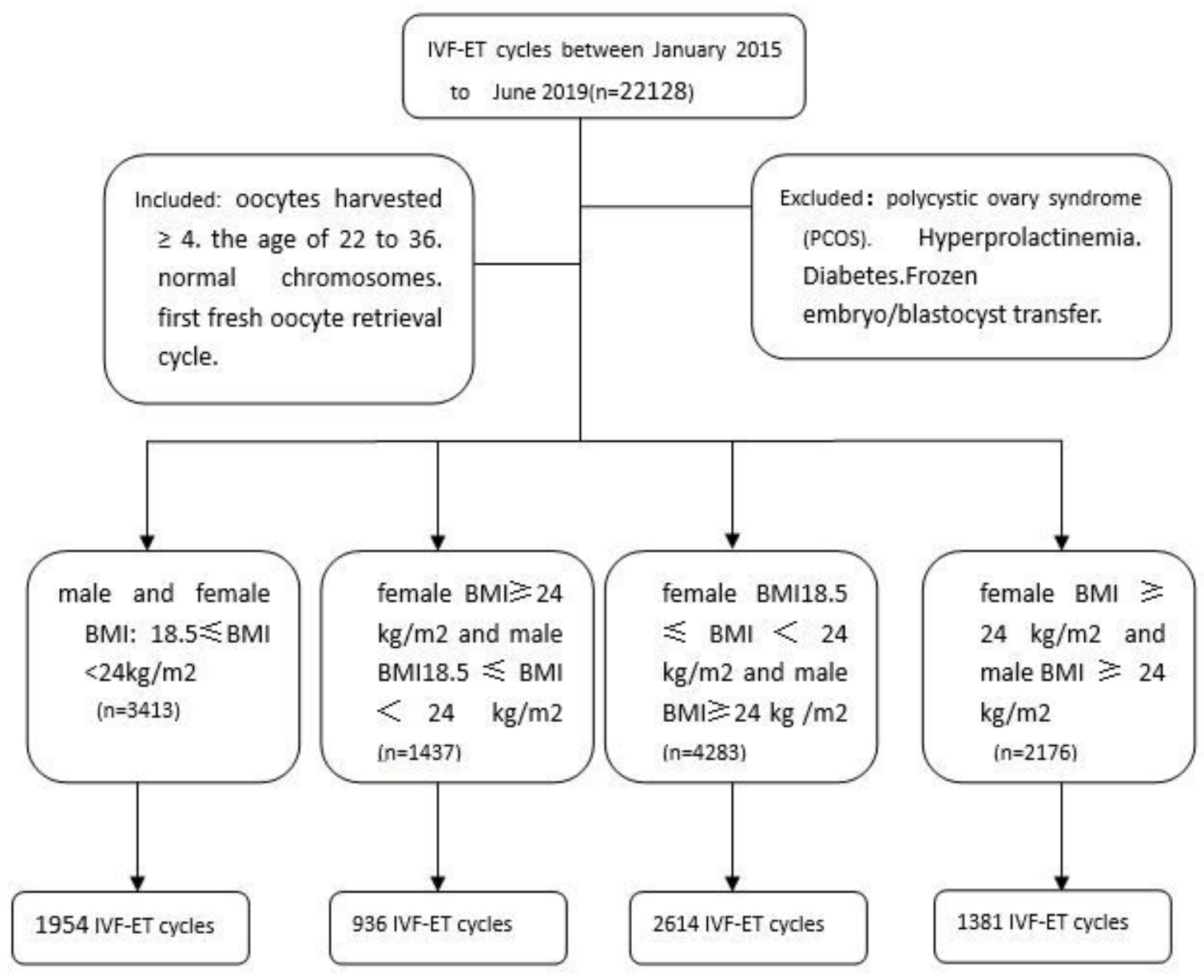

Figure 1

Flow-chart of the study cohort characteristics. 


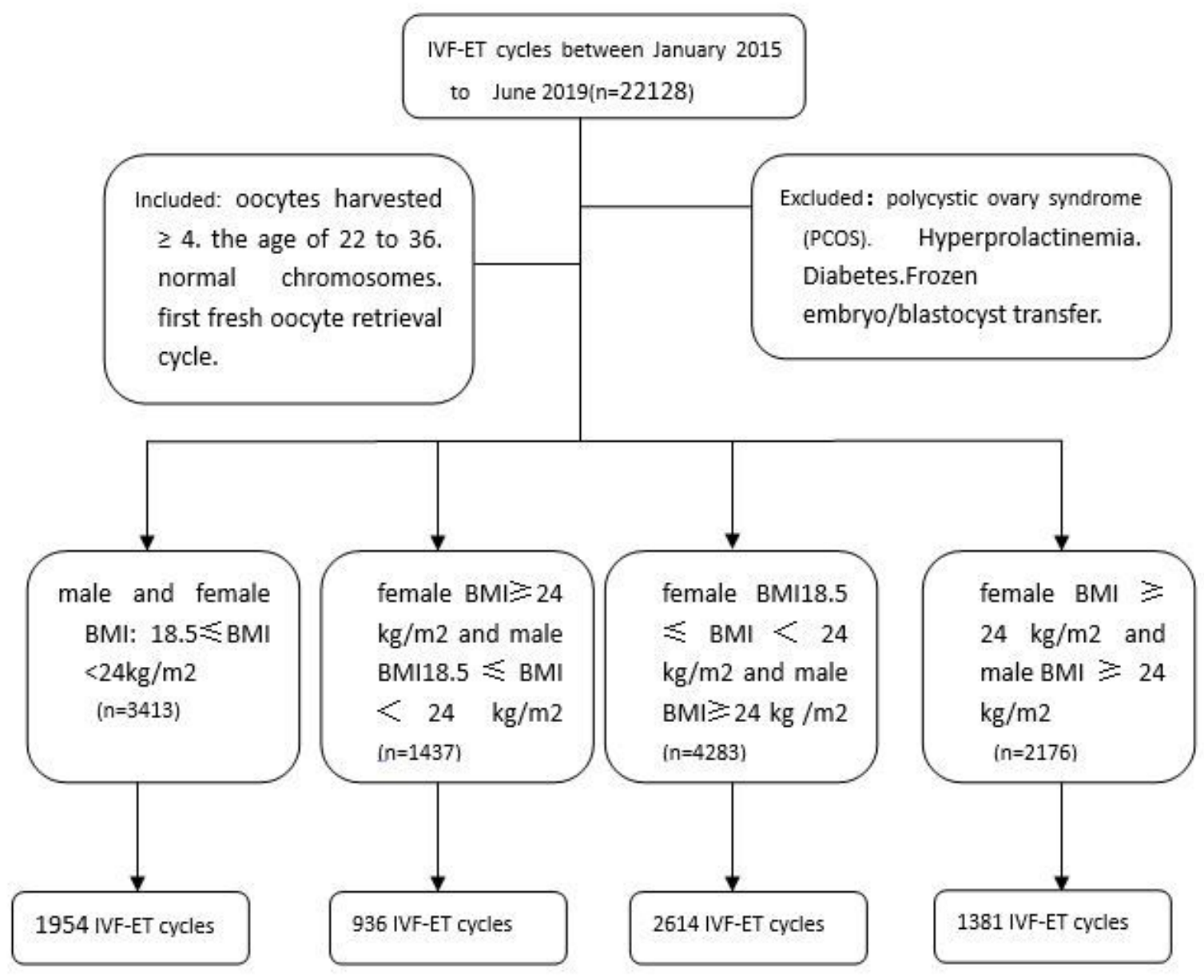

Figure 1

Flow-chart of the study cohort characteristics. 


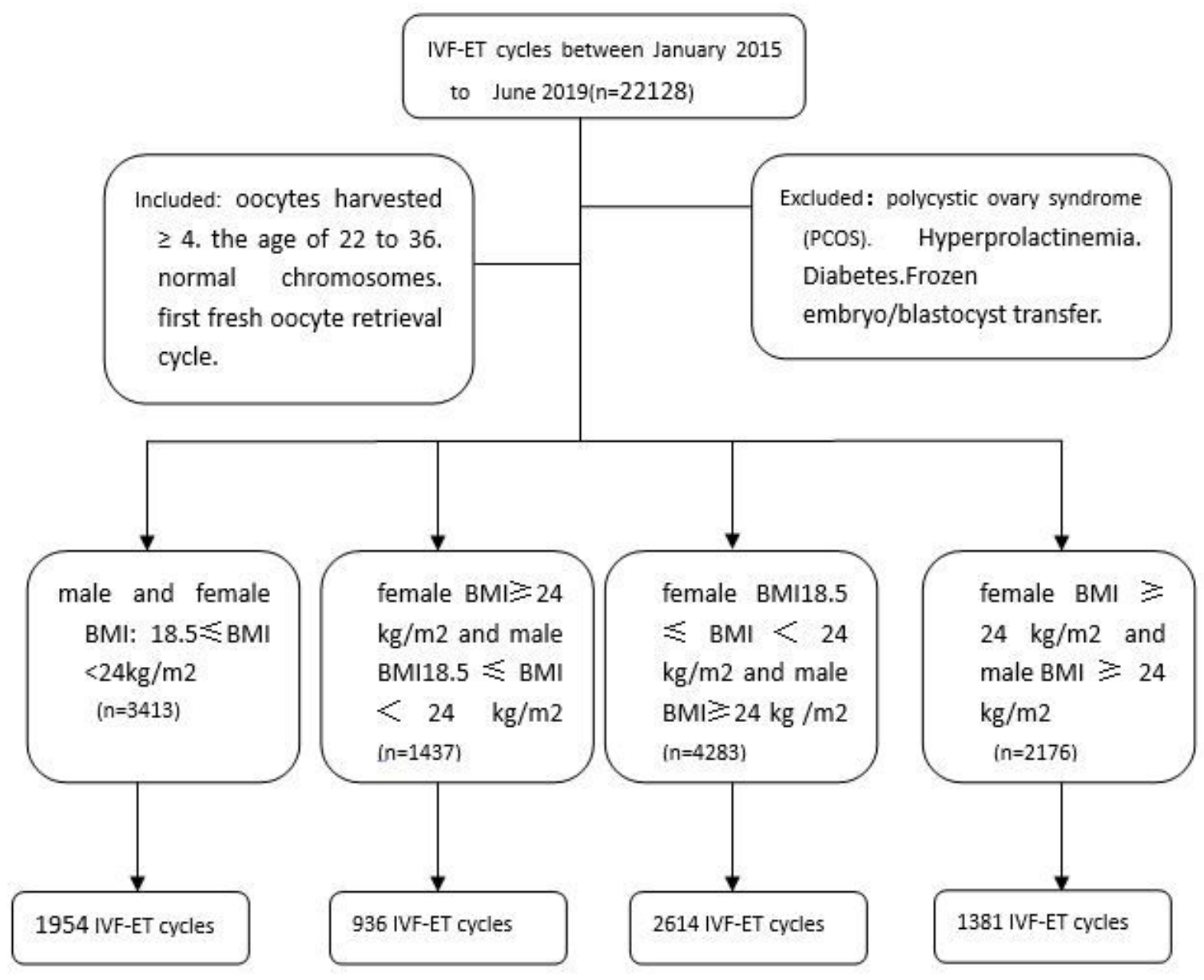

Figure 1

Flow-chart of the study cohort characteristics. 


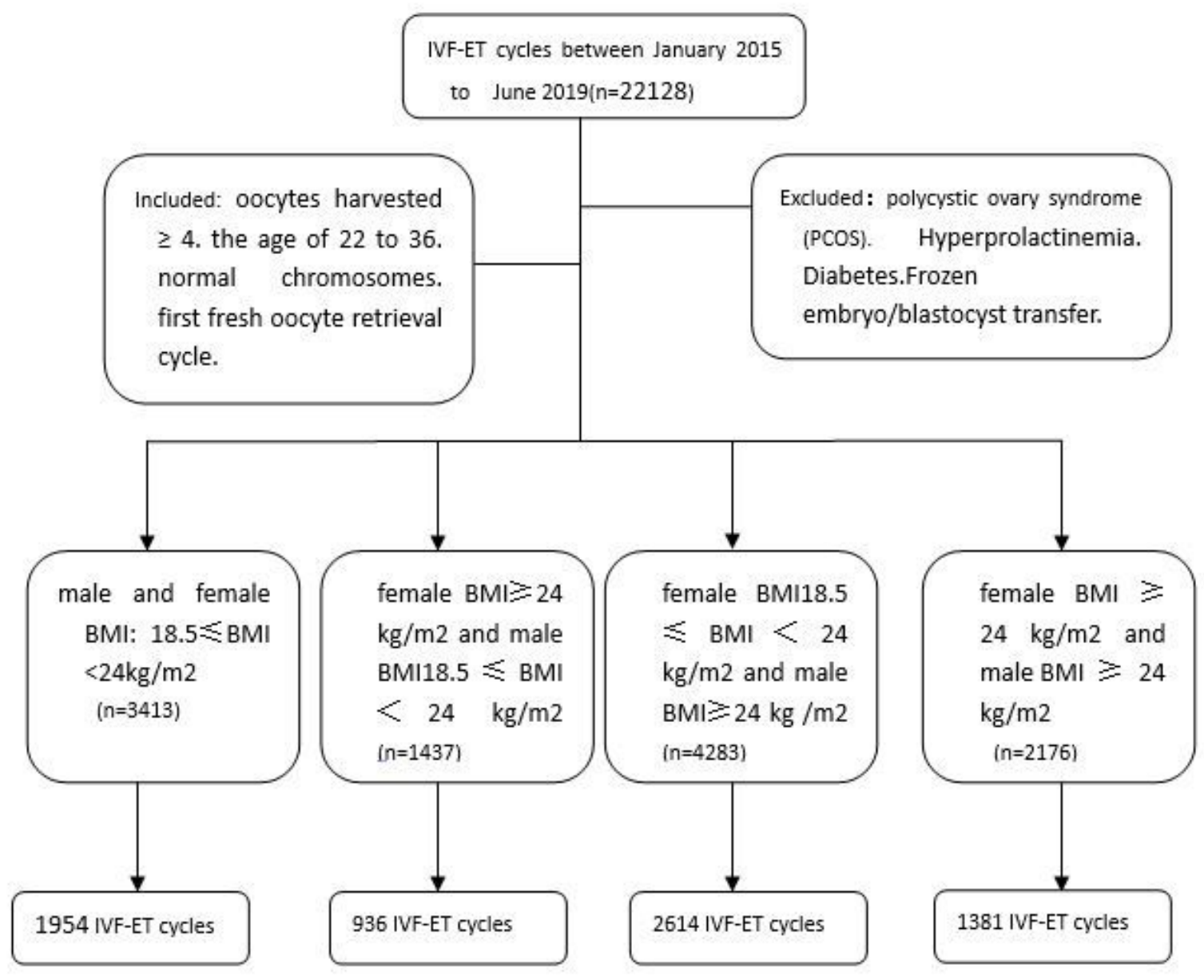

Figure 1

Flow-chart of the study cohort characteristics. 